\title{
SAUDAÇĀO PROFERIDA PELO \\ PROFESSOR FÁBIO KONDER COMPARATO AO NOVO TITULAR, PROFESSOR EROS ROBERTO GRAU
}

Renovamos hoje, com as galas de praxe, uma das cerimônias mais caras à nossa tradição: a posse solene de um Professor, no cargo culminante da carreira docente.

Dentre os méritos do novo Titular, permito-me destacar uma qualidade especial, que é o espírito de simplicidade e autocrítica. Vou, portanto, nela me apoiar para, confiadamente, participar desta solenidade com o duplo papel de crítico e personagem, de ator e espectador, nos moldes que Pirandello fixou para o teatro moderno.

A exata compreensão do que ora estamos todos a representar só pode ser dada, a meu ver, pela consideração do caráter acadêmico de nossa Faculdade, em sua dupla feição de escola e aristocracia cultural, segundo inveterada tradição.

A idéia acadêmica, de fato, seguiu dois caminhos bem definidos na história cultural do Ocidente.

A comunidade de mestres e discípulos, que reuniam temporariamente suas vidas no amor da sabedoria, tal como a criou Platão no jardim de Academos, embora eclipsando-se com o ocaso do mundo antigo, acabou renascendo na Itália dos quattrocento, com a Academia Florentina de Cosimo Medici. Esse renascimento não implicou, porém, a reprodução do venerável modelo platônico. $\mathrm{O}$ espírito comunitário das origens não ressurgiu nos tempos modernos, marcados já pelo autoritarismo, já pelo distanciamento individualista entre professores e alunos e o ânimo competitivo no seio de ambas as categorias. Teria havido, então, no universo escolar, a reprodução de estruturas próprias do sistema econômico capitalista, tal como preconizara, de resto, Adam Smith ao discutir a questão educacional, ou é toda a vida social moderna que se define pelo mesmo esquema estrutural, sem predominância de nenhum setor sobre o outro? Eis uma indagação estimulante para um cultor do Direito Econômico que, como o nosso homenageado de hoje, manifesta a acentuada tendência para transcender o campo de sua especialização. 
A verdade é que a renascença do ideal acadêmico, na Itália dos principados, já apontava para o caminho que a instituição haveria de seguir nos séculos posteriores. A academia deixava, aos poucos, de ser uma comunidade de mestres e discípulos, para transformar-se em círculo fechado de artistas e sábios, patrocinado pelo poder. $\mathrm{O}$ moderno academismo encontrou seu modelo definitivo com a instituição fundada por Richelieu, em 1635. Tudo passou a girar, afinal, em torno das idéias de acabamento e de consagração, em acentuado contraste com a comunidade platônica. $\mathrm{O}$ ingresso na academia já não significava uma iniciação ao saber, mas o reconhecimento de que a obra de toda uma vida chegara à sua perfeição e esse reconhecimento implicava o dever moral de se consagrar - no sentido original do termo - o acadêmico, ou seja, de apartá-lo da comunhão humana. A academia torna-se, propriamente, um panteão e os acadêmicos, por força dessa divindade eletiva, assumem a condição de imortais.

É desse novo sentido de academia que decorre o cerimonial de recepção de novos membros, que estamos agora a reproduzir. $O$ discurso de saudação deve ser uma justificativa de eleição efetuada, pelo enaltecimento da vida e da obra do eleito. Este, no discurso de agradecimento, é moralmente obrigado a analisar a personalidade de seu predecessor, de cuja cadeira toma posse, a justo título.

É interessante observar que a nossa Faculdade, nos primeiros tempos, encarnou esse duplo sentido da idéia acadêmica.

Ela foi, efetivamente, até a segunda metade do século passado, nas classes de preparação pelo menos, uma autêntica comunidade de professores e alunos, partilhando as mesmas habitaç̃es e o mesmo estilo de vida. Desse romantismo adolescente, restam-nos, para a memória, alguns poucos vestígios, principalmente o túmulo de Julius Franck, no menor de nossos pátios.

Mas temos sido também, ou pelo menos pretendido ser, desde as origens e sem descontinuar um olimpo de jurisconsultos, que, ao aqui ingressarem, como diria o poeta, "por obras valorosas se vão da lei da morte libertando" É esse caráter de panteão jurídico que, hoje, carece de toda legitimidade e escandaliza as novas gerações.

A rigor, o academismo celebratório de nossa Faculdade, explicável sem dúvida pelo deserto cultural do País à época de nossa fundação, introduziu-se 
na prática institucional à margem dos diplomas normativos. Foi uma espécie de fonte complementar do Direito, tal como a tradição católica em relação aos textos evangélicos. $\mathrm{E}$ analogamente a esta acabou por superar em muitos pontos o espírito da norma.

A própria palavra academia é estranha ao sistema normativo. A lei de 11 de agosto falava, modestamente, em cursos jurídicos. Foi o Decreto imperial de 17 de janeiro de 1885 que empregou, pela primeira vez, a denominação Faculdade, mantida até hoje.

Por esse mesmo Decreto, exigia-se que os novos lentes, na cerimônia de posse, fizessem um juramento "nas mãos do Diretor, perante a Congregação" A partir do Regimento Interno de 1929, passou-se a falar em "compromisso legal" ou "termo de compromisso" do professor; exigência essa, aliás, que ainda constava de nosso último Regimento a vigorar, o de 1937. O novo catedrático - precisava-se - deveria assentar-se, durante essa reunião congregacional, à direita do Diretor. Mas de discursos de saudação e agradecimento, no estilo da Académie Française, não se dizia palavra.

Já é mais do que tempo de se liquidar entre nós esse academismo fossilizado. Todos sabem que o seu rebento legítimo é a fixação de padrões oficiais de verdade, isto é, o dogmatismo. No caso específico do professor em final de carreira, a conotação de perfeição ou de obra acabada, que a admissão ao círculo dos imortais traz consigo, contraria frontalmente o serviço racional da Justiça, que todo cultor do Direito está, em consciência, obrigado a desempenhar. Para o corpo docente, o único verdadeiro dogma é a existência contínua de auto-superação, o empenho em jamais sofrer a própria mediocridade.

É indispensável, pois, que o novo Professor Titular, no momento em que atinge o ápice de seu cursus honorum, proclame, em alto e bom som, qual a contribuição que pretende trazer ao País, no campo da iurisprudentia. É curial que o representante da Congregação, ao receber o seu novo membro nato, exponha com franqueza o que dele esperam o mundo jurídico e esta Faculdade. Só assim ter-se-á superado, no elevado sentido do serviço público, o finado cerimonial acadêmico.

A consagração de um Professor de Direito, em nosso País, não pode advir do simples acesso à titularidade, ainda que pela via legítima do concurso, mas 
há de decorrer do reconhecimento público de sua contribuição ao deslinde dos grandes problemas nacionais.

Ora, a solução dos grandes problemas nacionais, neste Brasil do final do século, tem um nome: é o desenvolvimento econômico e social.

O novo Professor, que ora recebemos, tem se dedicado ex professo ao Direito Econômico. Coloca-se ele, portanto, na linha de frente de combate em prol da modernização econômica com justiça social.

Vossa Excelência, Senhor Professor Eros Roberto Grau, vem manifestando persistente vocação para, a partir de sua especialização científica, realizar a crítica do saber jurídico em geral. Vossa Excelência compreende, pois, pertinentemente, que a elaboração teórica de um Direito Econômico para o. Brasil não pode seguir a mesma linha de pensamento percorrida pela doutrina européia nesse ramo da teoria jurídica.

No excelente estudo sobre o pensamento jurídico de Hobbes e Leibniz, que Tullio Ascarelli compôs às vésperas de sua morte, observou ele, com agudeza, que a Ciência do Direito não se destaca da realidade jurídica, como simples reflexão sobre o seu objeto, a modo do que ocorre no campo das ciências da natureza. O que ela representa, na evolução histórica, não é senão um dos aspectos da evolução do próprio Direito. Aquilo que denominamos, por conseguinte, doutrina jurídica, bem analisadas as coisas, inclui-se entre os elementos do Direito positivo, tomado este em sua globalidade e não descarnado em puro normativismo. A compreensão da norma jurídica pelos sujeitos de Direito é, pois, parte essencial de sua existência lógica.

A premissa que me parece implícita nessa concepção é a admissão, compartilhada segundo entendo por Vossa Excelência, de que a ordenação jurídica constitui parte integrante da realidade social e de que, por conseguinte, a reflexão sobre o Direito Econômico brasileiro não pode ignorar a realidade sócio-econômica nacional, sob pena de derivar em puro abstrativismo.

Retomando a afirmação feita há pouco, chego à conclusão de que, se a chave de solução para os grandes problemas brasileiros é o desenvolvimento nacional, o Direito Econômico brasileiro - como, de resto, todos os ramos da teoria jurídica entre nós - só adquire coerência interna e funcionalidade social se dirigido ao desenvolvimento do País. 
A especificidade do Direito Econômico, porém, reside no fato de que somente ele se dirige, precipuamente, ao desenvolvimento nacional, somente ele tem, como seu objeto nuclear, esse fenômeno.

Ora, o desenvolvimento é hoje noção muito mais complexa e abrangente do que foi nos anos 50, quando a teoria desenvolvimentista começou a ser ensaiada no Brasil, por obra de alguns economistas vanguardeiros, entre os quais é dever realçar a figura de Celso Furtado. Hoje, já se estabeleceu razoável consenso no sentido de incluir, no conceito de desenvolvimento, não apenas o crescimento econômico endógeno ou auto-sustentado, mas também o processo de igualação das condições básicas da vida e o de melhoria constante da qualidade de vida.

A denominação desse ramo da ciência jurídica, portanto, analogamente ao que sucedeu com tantos outros, tornou-se claramente inadequada. O chamado Direito Econômico, cujo objeto precípuo no Brasil deve ser o desenvolvimento nacional, ocupa-se não apenas de políticas econômicas, mas de políticas sociais no sentido amplo, como as de educação e saúde, além de cuidar da organização política, administrativa e financeira de todo esse processo, na esfera estatal.

Entendido, assim, o desenvolvimento como a composição desses três processos interligados, é alarmante reconhecer que o nosso País vem sofrendo, há cerca de dez anos, uma nítida involução em todos eles.

No tocante ao crescimento econômico, se tivemos, entre 1965 e 1980 , uma taxa média de $8,8 \%$ ao ano, decaímos, entre 1980 e 1988 , para a média anual de $2,9 \%$, insuficiente para absorver o próprio crescimento demográfico. Essa desaceleração pronunciada, aliás, é grandemente explicável pela curva declinante do investimento global de origem interna, o qual, havendo crescido à taxa média de $5,9 \%$ a.a., entre 1965 e 1980, foi sendo reduzido na média anual de $3,2 \%$, nos primeiros oito anos da década de oitenta.

Em matéria de políticas sociais, convém ressaltar o fato auspicioso de que 0 Banco Mundial vem de reconhecer, em seu último relatório, que 0 desenvolvimento nacional dos países mais atrasados depende, basicamente, de um aumento do uso produtivo da capacidade de trabalho da população e que esse uso produtivo da força-trabalho supõe a larga adoção de políticas sociais, especialmente 
a de educação fundamental, a de saúde básica e de planejamento familiar. Ora, os gastos em educação da União Federal, que representavam $8,3 \%$ dos seus gastos totais em 1972, reduziram-se praticamente à metade dessa percentagem em 1988. Quanto aos gastos federais em matéria de saúde básica, para se ter uma idéia mais concreta de nossa negligência, é suficiente mencionar que o dispêndio da União Federal em 1988, entre nós, relativamente aos gastos globais, é percentualmente inferior aos dispêndios do governo central em países federais desenvolvidos, como os Estados Unidos ou a República Federal Alemã. Ele foi, no Brasil, de 9,5\%, contra $12,5 \%$ nos Estados Unidos e 18,2\% na Alemanha.

Tudo isto sem falarmos na questão da qualidade de vida, onde o progresso assustador da destruição ecológica vem colocando, de forma humilhante, o nosso País no centro das preocupações mundiais.

A reversão dessa tendência sinistra à desaceleração econômica, à desarticulação social e à degradação ecológica deveria iniciar-se, como parecia óbvio, pela modernização de nossas instituições políticas. A reconstitucionalização do País, cujo processo iniciou-se em 1985, era a ocasião áurea para tanto. Desgraçadamente, porém, como todos acompanhamos, o processo constituinte, maculado pela ilegitimidade de origem, produziu uma organização ultrapassada e ineficiente dos Poderes Públicos, radicalmente inepta para o desempenho da grande tarefa desenvolvimentista.

Essa inépcia da organização constitucional é claramente sentida em matéria de programação ou planejamento de políticas públicas. Vossa Excelência, que se havia ocupado do tema sob o aspecto da estrutura da norma jurídica, em sua tese de livre-docência, voltou ao assunto, agora de forma especificamente dirigida à análise da ordem econômica constitucional, em sua monografia de titularidade.

Tenho porfiado há anos, sem o menor êxito, em demonstrar que a realização de políticas públicas é a principal função a ser desempenhada pelo Estado contemporâneo, mormente em paises subdesenvolvidos, e que o exercício dessa função exige uma nova organização dos Poderes Públicos. Tenho insistido em demonstrar, sempre em vão, que, assim na empresa privada como no Estado, não há desenvolvimento de políticas sem planejamento e que planejamento não significa, de forma alguma, estatização; que o descontrole atualmente sofrido no setor das empresas estatais é fruto não do excesso de planejamento, mas, bem ao 
contrário, da ausência total de previsão, análise global e programação a longo prazo, as quais formam a essência da atividade planejadora.

Aí tem, por conseguinte, Vossa Excelência, Senhor Professor Eros Grau, tudo aquilo que, em meu entender, o mundo jurídico brasileiro e esta Faculdade em particular estão autorizados a esperar de sua atividade de Professor Titular. Uma reflexão contínua sobre o Direito Econômico, decididamente dirigido ao desenvolvimento, reflexão essa que, enriquecida pela prática docente, se encaminha para a elaboração de soluções jurídicas concretas, tanto no plano legislativo quanto no administrativo. Em suma, a atuação intelectual competente em defesa da dignidade humana na imensa massa proletária.

A Faculdade de Direito da Universidade de São Paulo saúda-o com alegria e confiança. 